\title{
A SYSTEMATIC REVIEW AND META-ANALYSES OF THE POTENTIAL LOCAL ECONOMIC IMPACT OF TOURISM AND LEISURE CYCLING AND THE DEVELOPMENT OF AN EVIDENCE-BASED MARKET SEGMENTATION
}

\author{
MIKE WEED,* CHRIS BULL,* MAT BROWN,* SUZANNE DOWSE,* JANE LOVELL,* \\ LOUISE MANSFIELD, † AND IAN WELLARD* \\ *Centre for Sport, Physical Education and Activity Research (SPEAR), \\ Canterbury Christ Church University, Canterbury, UK \\ †School of Sport and Education, Brunel University, Uxbridge, UK
}

\begin{abstract}
Through a systematic review and meta-analyses of worldwide evidence, this article provides estimates for spend per person per day of overnight (£43.33), non-overnight (£7.95), and all (£13.38) tourism and leisure cyclists. A further meta-analysis to inform local policy, provision, and local economic impact strategies provides evidence for seven tourism and leisure cycling market segments (Near Residents, Far Residents, Near Day Trippers, Far Day Trippers, Near Holidayers, Far Holidayers, Cycle Tourers), and their associated behaviors and spending patterns. Over three quarters of economic activity attributable to tourism and leisure cycling (77\%) is shown to be derived from cycling tourism, thus representing additional local economic impact. In conclusion, the use of market segmentation to derive local economic impact estimates is discussed. The importance of considering how far cycling tourism affects trip decisions, rather than whether cycling tourism is the prime trip purpose, is highlighted in deriving robust economic impact estimates. Finally, because the Cycle Tourers market segment contributes less than $2 \%$ of market volume and value, future research might usefully focus on less dedicated but more prevalent casual recreationalist cyclists, who are interested in shorter trips, with more stops for refreshments and socializing, and who often travel in family groups.
\end{abstract}

Key words: Cycling tourism; Sports tourism; Systematic review; Meta-analysis; Economic impact

\section{Introduction}

Cycling tourism is a growing area of niche interest within the study of not only sports tourism but also of tourism more generally, with examples of research existing in most developed countries around the world (e.g., Lumsdon, Downward, \& Cope, 2004; Ritchie, 1998; Simonsen, Jorgensen, \& Robbins, 1998). Some parts of this work have focused on specific types of cycling tourism (such as Bull's 2006 study of racing cyclists), policy aspects 
such as sustainability (Downward \& Lumsdon, 2001; Lumsdon, 2000; Lumsdon et al., 2004), or major cycling events such as the Tour de France (Bull \& Lovell, 2007; Desbordes, 2007). Beyond the academic sphere, coverage can also be found in more popular publications (e.g., Breakell, 2006; Lumsdon, 1996), publications linked to a particular interest group (Sustrans, 1999), or various reports that focus on economic impacts and tourism growth in particular regions or destinations (e.g., EcoGIS, 2002; Fraietta, 2004; Greenwood \& Yeoman, 2006; Lumsdon et al., 2004; Maine Department of Transportation, 2001; Mintel, 2007; Picton \& Bull, 2003; Wales Tourist Board [WTB], 2002).

Unsurprisingly, work focusing on the potential economic impacts of cycling tourism has attracted the attention of local and regional policy makers, planners, and providers, either those seeking to capitalize further on existing cycling provision in their area or those seeking to develop new cycling provision for local and regional economic benefit, mostly linked to the attraction of day-tripping or overnight cycling tourists. While some places have sought economic impacts through hosting or attracting cycling events, a more widespread strategy has been to attract recreational cycling tourists to designated cycle routes, trails, or paths (Breakell, 2006; Cope et al., 2003; Faulks, Ritchie, \& Fluker, 2007; Greenwood \& Yeoman, 2006; Lumsdon, 1996; Weed \& Bull, 2009). Some such routes or trails are local and self-contained, such as the rail trails that have been developed from abandoned railways lines, a development that is especially prominent in Australia, or the many circular trails such as the 47-mile Purbeck Ride in Dorset, UK or the 25-mile ride round Rutland Water reservoir in Leicestershire, UK. Many others, however, are part of wider networks. For example, cycling routes and cycle tourism developments in Europe have been integrated into sustainable development and transport policies leading to the development of well-planned regional, national, and pan-European networks (Faulks et al., 2007). Similar networks can be found elsewhere in the world: for example, in the US (the US Bicycle Route System), in the various regions of Australia, the Trans Canada Trail, and the National Cycleway project in New Zealand. However, although research such as that noted above reports that positive local economic impacts can be realized from tourist visits to cycle routes, trails, and paths (e.g., EcoGIS, 2002; Fraietta, 2004; Greenwood \& Yeoman, 2006; Lumsdon et al., 2004; Mintel, 2007; Picton \& Bull, 2003; WTB, 2002), this is of little use to policy makers, planners, and providers in developing provision, as there is very little empirically informed research on the different spending patterns and behavioral profiles of cycling tourists, nor on how far recreational cycling tourists might be considered a homogenous group, or whether some form of segmentation is possible.

Consequently, the aim of this article is to develop an empirically informed segmentation of the tourism and leisure cycling market ${ }^{1}$ that identifies the economic impact ${ }^{2}$ attributable to various market segments and that can thus be used to inform provision and promotion strategies by local and regional policy makers, planners, and providers. To do so, it draws on a worldwide systematic review of research evidence on the behaviors and spending of tourism and leisure cyclists, and conducts meta-analyses on those quantitative data returned that are amenable to such an approach, which is informed and guided by wider data and insights from other studies returned in the systematic review. However, before turning to the detail of the systematic review and meta-analysis, the utility of existing economic impact studies and previously proposed approaches to cycling market segmentation are reviewed.

\section{Economic Impact Studies and Segmentation Approaches}

In a "briefing" on cycling tourism, Sustrans (1999), a UK charity that encourages and advocates sustainable transport, provide some bullish estimates for the size and scope of cycling tourism throughout Europe. Sustrans (1999) suggest that Austria's Danube Trail attracts over 1.5 million visitors a year while Germany’s Bodensee Cycle Trail attracts an estimated 380,000 riders, producing an economic contribution of $€ 75$ million to the region. Furthermore, they also estimate that the whole of Europe is expected to generate $£ 14$ billion in cycle tourism revenue per year by 2020 (Sustrans, 1999). Beyond Europe, Faulks et al. (2007) suggest that direct spending in Maine (USA) by over 2 million cycling tourists totaled $\$ 36.3$ million, and in 
New Zealand 3\% of overseas tourists and 1.6\% of domestic holiday makers cycle between destinations in the South Island, which is worth $\$ 72$ million per annum to the economy. It is estimated that $10.5 \%$ of Australians participate in cycling (Australian Sports Commission, 2005, quoted in Faulks et al., 2007) and that the vast majority (86\%) cycle for fun and leisure. However, such aggregate estimates for the value of tourism and leisure cycling (some of which represent only cycling tourism, while others also include leisure cycling by local residents) do little to help local policy makers, planners, and providers decide what types of recreational cycling provision they might make to maximize economic benefit from cycling tourism.

In the UK, Mintel (2007) suggest that 450,000 British people spent $£ 120$ million on cycling holidays in the UK in 2005 with an additional 2.25 million holidays involving some kind of 'incidental' cycling such as a day's bike hire or a bike sightseeing tour. Furthermore, market growth was suggested, as $16 \%$ of adults (8 million) had already been on some kind of cycling holiday with a further $12 \%$ (6 million) having not yet taken a cycling holiday, but wanting to do so in the future. Greenwood and Yeoman (2006) estimated that cycling tourism to Scotland from UK residents in 2003 was worth $£ 219$ million and represented 1 million trips. These figures involved cycling as a main purpose of trip (cycling holidays), accounting for £20 million and 100,000 trips, and cycling as part of a wider holiday with £199 million expenditure and 900,000 trips (Greenwood \& Yeoman, 2006). Both the Mintel (2007) and Greenwood and Yeoman (2006) data suggests that there may be some value in thinking about different types of cycling tourists according to how important or central cycling is within the tourist trip, or perhaps more usefully, how far it plays a role in the trip decision.

In the wider sports tourism literature, some authors (e.g., Gammon \& Robinson, 2003) have suggested that sports tourism comprises trips where sport is dominant and trips where tourism is dominant. This has led to the categorization of sports tourism by a number of authors (e.g., Gammon \& Robinson, 2003; Robinson \& Gammon, 2004; Sofield, 2003; Standeven \& De Knop, 1999) within a framework that makes a distinction between "sports tourism" (where sport is the primary purpose of the trip) and "tourism sport" (where tourism is the primary purpose). This leads to an analysis of sports tourism at the "trip" level, with entire trips designated as either sports tourism or not sports tourism. For assessing economic impact, this provides a clear distinction between those trips where the economic impact should be attributed to the form of sports tourism in question (in this case, trips where cycling tourism is the prime purpose), and those that should not (i.e., trips where cycling tourism is an incidental or secondary purpose). However, as Weed and Bull (2009) suggest, an analytical framework that can only attribute entire trips as either cycling tourism or not cycling tourism does not allow for a particularly sophisticated or granular analysis of the role of cycling tourism in trip decisions. Furthermore, such a framework is likely to underestimate the economic impact attributable to cycling tourism, as it does not include economic impact generated on trips where cycling tourism is not the primary purpose, but where it has played a role as a differentiating factor in trip decisions about where to go on a particular trip (Weed \& Bull, 2009). In such cases, the economic impact of the trip might quite legitimately be attributed to cycling tourism, because without local provision for cycling tourism activity, the trip would have been taken elsewhere.

Most definitions of cycling tourism only include activities in which the cycling is a fundamental and significant part of the trip and thus exclude incidental ("spontaneous") cycling, such as an occasional cycle ride on holiday (see, e.g., Lumsdon, 1996; Ritchie, 1998; Sustrans, 1999). Even the definition proposed by the South Australian Tourism Commission (2005), which is generally regarded to be broader in scope than most others (Lamont, 2010; Weed \& Bull, 2009), does not allow for incidental cycling. In fact, the only existing definition that comes close to accommodating this is that encountered in Simonsen et al.'s (1998) study where they define a cycle tourist as "a person ... who at some stage of other during his or her holiday uses the bicycle as a mode of transportation" (p. 20) but they then qualify that by adding "to whom cycling is an important part of this holiday." Thus, given that most, if not all, definitions of cycling tourism do not consider trips on which cycling is a secondary purpose, any economic impact studies of cycling tourism that utilize such definitions are unlikely to 
derive robust and complete economic impact estimates. For example, one of the few cycling "segmentation" frameworks (although it is more of a categorization than a segmentation in that it is not empirically derived) is that proposed by Sustrans (1999), which includes three specific categories of cycling tourism, and an "other” category.

The first category Sustrans (1999) identify is “cycling holidays," representing those trips where cycling is the prime purpose, and this is the simplest category from which to estimate economic impact, as the entire economic outcomes of the trip can be attributed to cycling. However, the second category, "holiday cycling," in which the purpose of the trip is not cycling, but cycling is one of a number of activities on a trip, should (as noted above) also be at least partially considered in economic impact assessments because the opportunity to cycle may be a differentiating factor between destinations. Estimating the impact of this type of cycle tourism is more difficult, because the "additionality" of the impact attributable to cycling must be established and, because of this difficulty, many previous studies have omitted to include the economic impact from "holiday cycling." The third category, “cycling day visits," is also an economic generator, providing the day-trippers are visiting from outside the local economy. While the value per visit of such trips is often lower than cycling holidays or holiday cycling, the volume of trips is often greater. The final category identified by Sustrans is an "other" category, which includes a range of cycling activities, some of which might be considered cycling tourism and some of which are more appropriately thought of as leisure cycling.

While the Sustrans (1999) framework might be intuitively appealing, not least for its simplicity, it is not based on any extended analysis of empirical evidence, but on a rather simple conceptual distinction between prime purpose, secondary purpose, and day-tripping cycling tourists. Furthermore, as Bull (2006) notes, the framework provides little or no discrimination between infrequent and frequent cyclists or between casual participants and committed cycling tourists (cf. Green \& Jones, 2005) and it is limited in its ability to identify variations in spending patterns and behaviors in market segments.

Faulks et al. (2007) suggest that, rather than seeking to segment "types" of cycling tourism, the "wide variety of individuals and potential market segments" (p. 14) that constitute the range of cycle tourism should perhaps be differentiated on the basis of "motivations" as well as "activity." Based on the work of Simonsen and Jorgenson (1996), Faulks et al. (2007) suggest that a continuum ranging from cycling enthusiast, or hard core cyclist, to occasional cyclist could be considered, and cite the South Australian Tourism Commission (2002), who suggest that cycling tourists can be categorized as being dedicated, interested, or incidental/opportunistic. This report also noted that individuals are not necessarily confined to one group, as cycling activities might take on different levels of importance for different trips or different parts of trips. The implications of such an approach for assessing economic impact is an assumption that different types of cycling tourist (as opposed to different types of cycling tourism) are likely to be associated with different behaviors and different spending patterns, but that individuals may fulfill different cycling tourist "roles” (cf. Gibson \& Yiannakis, 2002) at different times or on different trips. This, of course, starts to become useful information in helping to inform local strategies for cycling tourism planning, provision, and promotion.

However, other than making a distinction between trips where cycling tourism is a prime purpose and trips where it is not, to date there is little evidence that economic impact studies have sought to segment cycling tourists (rather than cycling tourism). For example, estimates of economic impact for specific destinations or types of destination include the 2005 English Leisure Visits Report (Natural England, 2006), which estimated that there were 1.36 million cycle tourism trips to the English countryside producing an overall revenue of approximately $£ 40$ million, and 110,000 cycle tourism trips to national parks worth $£ 22$ million. At a more local level, Regeneris Consulting (2005) estimated that there were 116,000 holiday makers in North East England in 2003 who participated in cycle tourism, producing between $£ 4$ million and $£ 7$ million income and supporting between 400 and 600 fulltime jobs, and a subsequent report (Sustrans, 2007) suggested that during 2006 four long-distance routes of the National Cycle Network directly contributed £9.6 million to the North East economy and $£ 13.4$ million to the wider economy. However, it is 
difficult to know how to assess the reports for the volume and value of cycling tourism in the UK and Scotland noted earlier alongside those given here for the English countryside and for the North East of England, as they each refer to different types of provision, on different geographic scales, and most likely attracting very different types of cycling tourists, and in some cases including leisure cycling by local residents. Hence, there is the need for the type of meta-analysis offered in this article to provide some standardized and comparable data on which decisions about provision and promotion at a local level can be based.

\section{Systematic Review and Meta-Analysis}

There has been an increasing interest in collating evidence to inform policy in recent years, and increasingly the traditional literature review is being seen as inadequate in accessing the best evidence for policy decisions. In 2001 the Economic and Social Research Council (ESRC) in the UK funded the establishment of an Evidence Network dedicated to the improvement of the evidence base for policy and practice in the social sciences. This Evidence Network has promoted and developed the use of the systematic review procedure (Coren \& Fisher, 2006) to collate research evidence and inform policy development, and it is this procedure that has been used to search, collate, and appraise the evidence base for the local impacts of tourism and leisure cycling.

As recommended in the literature, a formal review panel comprising the seven authors was formed (Coren \& Fisher, 2006; Tranfield, Denyer, \& Smart, 2003; Weed, 2006). At an initial meeting, the review question was agreed as: What are the potential local economic impacts of cycling tourism in the UK? The UK context was included because the review was funded by a UK county authority; however, the panel agreed that worldwide sources should be searched, but that UK data would be given greater weighting in the analysis (this was later operationalized by weighting UK data 4:1 against non-UK data). The panel also agreed that spending by local leisure cyclists needed to be included in the analysis to allow such spending to be identified and removed to provide estimates of the economic impact of cycling tourism. The initial meeting also outlined exploratory searches to refine search terms and identify appropriate databases to answer the review question (Coren \& Fisher, 2006). Following exploratory searches, four databases were included in the formal searches: Sports Discus (sport, exercise, leisure, and tourism), CINAHL (health care), ASSIA (geography and sociology), and Business Source Premier (advertising, marketing, and communication). The search protocol is outlined in Table 1.

Once duplicates across the databases were removed, this search returned 3,229 sources; the titles of the returns were reviewed by the review panel for inclusion on the basis of relevance to the review question (Coren \& Fisher, 2006; Tranfield et al., 2003), and 419 articles were retained. The abstracts for the 419 sources were divided between the seven panel members for independent review. Each source was reviewed by two panel members for inclusion on the basis of relevance to the review question and no one member reviewed the same combination of sources. Where there was disagreement on inclusion, a third panel member also assessed the source (Coren \& Fisher, 2006; Tranfield et al., 2003). On the basis of this filtering process 111 sources were identified for full text retrieval.

The review panel also met to discuss whether it appeared that any significant papers or bodies of

Table 1

Systematic Review Search Protocol

\begin{tabular}{ll}
\hline $\begin{array}{l}\text { Date range } \\
\text { Search }\end{array}$ & $\begin{array}{l}\text { January 1990-December } 2010 \\
\text { combination }\end{array}$ \\
& AND ${ }^{*}$ OR bike OR bicycl* OR BMX) \\
& (Tourism OR leisure OR holiday* OR rec- \\
& reation* OR sport* OR health OR Travel \\
& OR rid* OR racing OR exercise OR sus- \\
& tainab* OR transport OR route OR trail) \\
& NOT \\
& ('power output' OR physio* OR crank OR \\
& menstrual OR musc* OR Biomech* OR \\
& endurance OR medicine OR nutrition OR \\
& Performance OR drug* OR Athlet* OR \\
& biolog* or motor*) \\
& All databases: English language. \\
& Sport Discus: sources - Book analytic; book \\
& review; Journal article (peer reviewed); \\
& thesis/dissertation; serial publication and \\
& monograph/government publication. \\
\hline Limitations &
\end{tabular}

aThe * symbol is a wildcard. For example, "cycl*" will return the terms cycle, cycling, cyclist, etc.

${ }^{b}$ This third-level search was not included for the CINHAL or ASSIA databases as they do not support this functionality. 
literature were missing and to consider how "gray" literature and other associated sources of information might be accessed. Following this meeting, specific searches of the publication history of some key authors were added, as well as searches of potential sources of gray literature, including the websites of the Regional Development Agencies, Natural England, and regional tourist boards. Searches of, and contacts with, these sources of gray literature were ongoing throughout the project, with full text sources being retrieved where possible. In total, these additional searches added a further 26 sources, while 16 of the 111 sources from the electronic searches were irretrievable, resulting in a total of 121 full text sources.

The 121 full text sources were each reviewed by two panel members, and 54 sources that were identified as providing only contextual information about cycling tourism were excluded. Where there was disagreement, a third panel member also assessed the source (Coren \& Fisher, 2006; Tranfield et al., 2003). In parallel to this process, the 121 sources were "reference mined" for additional sources, resulting in the retrieval of a further 17 sources.

The 84 remaining sources were distributed among the panel for formal quality appraisal. Each source was independently assessed by two different members using a quality appraisal form designed for this review, and where there was disagreement a third member also assessed the source (Coren \& Fisher, 2006; Tranfield et al., 2003). Quality criteria included: specificity and relevance of the source, nature of evidence included, measures included, clarity and transparency of methods, relevance to contemporary UK context. The quality appraisal resulted in the exclusion of a further 34 sources, leaving 50 sources included in the review. The final 50 sources are summarized in Table 2.

Twelve of the 50 sources included sufficient data to allow spend per person per day figures to be calculated, and these sources were included in metaanalyses of economic impact (Wolf, 1986). Four datasets were retrievable in full, and thus could be subjected to a meta-analysis to derive market segments. The remaining 38 sources were used to guide and inform the meta-analyses. For example, Downward and Lumsdon (2001) suggested that a significant proportion of cyclists like to access cycle routes by cycle (as opposed to arriving by car), and so the market segmentation meta-analysis included a consideration of this variable as a substantive moderator.

Weed (2006) noted that meta-analysis is the most used formal synthesis approach in tourism studies; however, examples of its use (e.g., Crouch, 1995; Lim, 1999; Wagner, 2002) are far more limited than in studies of sport and leisure behavior (e.g., Chatzisarantis, Hagger, Biddle, Smith, \& Wang, 2003; Manfredo, Driver, \& Tarrant, 1996) or in economics (e.g., Card, Kluve, \& Weber, 2010; Hudson, 2001). The perception of meta-analysis is often as a method that simply estimates an overall "effect size" (in this case, economic impact) from the effect sizes of individual studies, thus giving greater "power" to the overall statistic (Wood, 2000). However, meta-analysis also uses statistical procedures to "correct" for or standardize variations in studies that may arise both from a range of methodological sources, such as differing sampling procedures, and from substantive moderators (Hunter \& Schmidt, 1990). This allows meta-analysts to identify whether inconsistencies across studies are due to errors or different methodological assumptions, or to genuine substantive moderators. In the four datasets included in the meta-analysis of market segments, for example, different assumptions had been made about what constituted local residents, and these different assumptions were corrected for to standardize the meta-analyzed dataset by distance traveled. In terms of substantive moderators, the differing proportions of cyclists both traveling different distances to the trails and staying overnight were identified as key substantive moderators on the overall economic impact figures calculated. Consequently, the segmentation of cycling tourists presented is primarily based on distance traveled and overnight stay variables.

\section{Economic Impact Meta-Analysis}

A number of studies that provide an overall figure for the regional or local economic impact of tourism and leisure cycling were returned in the search, although in one case the impact is for an entire country. The direct economic impacts suggested by these sources, inflated and converted to 2010 UK prices, are summarized in Table 3. 
Table 2

Summary of Sources Included in the Review

Sample

Size (Where

Author (Date)

Publication Type

Topic

Location

Evidence

Quantitative)

Bauman et al. (2008)
Berrigan et al. (2006)
Bhat \& Lockwood

(2004)

Bowker et al. (2007)

Bowles et al. (2006)

Brown et al. (2009)

Cavill and Davis

(2007)

Chiu and Kriwoken

(2003)

Cope et al. (2003)

Cope et al. (1998)

de Geus et al. (2008)

Dill (2009)

Downward and

Lumsdon (2001)

Downward et al.

(2009)

Faulks et al. (2008)

Faulks et al. (2007)

Forward (1999)

Garrard (2003)

Garrard et al. (2006)

Gatersleben and

Haddad (2010)

Greig (2005)

Institute of Transport

\& Tourism (2008)

Kahlmeier et al.

(2010)

Kamphuis et al.

(2008)

Lawlor et al. (2003)

Lumsdon (1999)

Lumsdon (2000)

Lumsdon et al. (2004)

Lumsdon et al. (2009)

Mann and Absher

(2008)

Mason and Leberman

(2000)

Mintel (2009)

Moore et al. (2006)
Report

Refereed journal

Refereed journal

Refereed journal

Refereed journal

Refereed journal

Report

Refereed journal

Refereed journal

Refereed journal

Refereed journal

Refereed journal

Refereed journal

Refereed journal

Conference report

Report

Conference paper

Report

Report

Refereed journal

Conference paper

Report

Refereed journal

Refereed journal

Refereed journal

Conference paper

Refereed journal

Refereed journal

Report

Refereed journal

Refereed Journal

Report

Refereed journal
Promoting physical activity

through cycling

Active transport: health impacts

Promoting physical activity

Recreational trail impact analysis

Cycle events: Participants behav-

ior \& motivations

Measuring cyclist motivations

Health benefits of cycling

Environmental \& social impacts

of mountain biking

National Cycle Network: user \&

impact analysis

Cycle route economic impact \& user analysis

Psychosocial \& environmental

predictors of cycling for

transportation

Promoting cycling (infrastructure)

Developing recreational cycle

routes: user needs

Cycle route user \& economic

impact analysis

Cycle tourist motivations

Cycle tourism in Australia

Behavioral factors affecting the intention to cycle

Promoting cycling for women

Promoting cycling for women

Cyclists' identities, behaviors

\& motivations

Cyclists motivations

Cycle trail economic Impact analysis

Health economic assessment tool

(HEAT) for cycling and walking

Environmental \& socioeconomic

determinants of cycling

participation

Environmental strategies to promote walking and cycling

Tourism potential of cycle routes

Cycle tourism: integrating

transport, tourism and recreation

Cycle route user analysis

Cycle tourism in Europe

Managing outdoor recreation

facilities

Local planning for recreational

cycling

UK Cycling Holiday data

Promoting cycling among

excluded groups
Australia Review

$\begin{array}{lll}\text { US } & \text { Secondary } & n=55,151 \\ \text { US } & \text { Secondary } & n=15,000\end{array}$

US Primary $n=1,036$

Australia Primary $n=918$

Australia Primary $\quad n=422$

UK Review

Australia Primary $n=255$

UK Primary $n=1,464$

UK Primary $n=1,000$

Belgium Primary $n=343$

$\begin{array}{ccc}\text { USA } & \text { Primary } & n=166 \\ \text { UK } & \text { Primary } & n=191\end{array}$

UK Primary $n=373$

Australia Primary $n=749$

Australia Review

Holland, Spain, Primary $n=354$

\& Denmark

Australia Primary

Australia Primary

UK Primary

$n=2,403$

$n=244$

$\begin{array}{cc}\text { Australia } & \text { Primary } \\ \text { UK } & \text { Primary }\end{array}$

International Review

Australia Primary $n=2,349$

UK Secondary $n=7,300$

UK Secondary

UK Review

UK Primary $n=410$

Europe

Germany

Primary

$n=805$

New Zealand Primary $\quad n=46$

$\begin{array}{lll}\text { UK } & \text { Primary } & n=623 \\ \text { UK } & \text { Primary } & n=934\end{array}$


Table 2

Summary of Sources Included in the Review (Continued)

\begin{tabular}{|c|c|c|c|c|c|}
\hline Author (Date) & Publication Type & Topic & Location & Evidence & $\begin{array}{l}\text { Sample } \\
\text { Size (Where } \\
\text { Quantitative) }\end{array}$ \\
\hline Papon (1999) & Conference paper & Classification of cyclists & France & Secondary & \\
\hline Picton \& Bull (2003) & Report & Cycling trail user analysis & UK & Primary & $n=364$ \\
\hline Pucher et al. (2010) & Refereed journal & $\begin{array}{l}\text { Relationship between active } \\
\text { travel and physical activity, } \\
\text { obesity and diabetes }\end{array}$ & International & Secondary & \\
\hline Pucher et al. (2011) & Refereed journal & $\begin{array}{l}\text { Comparative case study: cycling } \\
\text { trends and policies }\end{array}$ & Australia & $\begin{array}{l}\text { Primary } \\
\text { \& sec- } \\
\text { ondary }\end{array}$ & \\
\hline $\begin{array}{l}\text { Quinn and Chernoff } \\
\text { (2010) }\end{array}$ & Report & $\begin{array}{l}\text { Mountain biking and } \\
\text { environmental impacts }\end{array}$ & Canada & Review & \\
\hline Rissel et al. (2010) & Refereed journal & Cycling demand \& promotion & Australia & Primary & $n=1,450$ \\
\hline Ritchie (1998) & Refereed journal & $\begin{array}{l}\text { Cycle Tourism: demand, plan- } \\
\text { ning, \& management }\end{array}$ & New Zealand & Primary & $n=321$ \\
\hline Ritchie et al. (2010) & Refereed journal & $\begin{array}{l}\text { Cycle tourists: motivations } \\
\text { \& behaviors }\end{array}$ & Australia & Primary & $n=564$ \\
\hline $\begin{array}{l}\text { Simonsen et al. } \\
\text { (1998) }\end{array}$ & Report & $\begin{array}{l}\text { Cycle Tourism: economic } \\
\text { \& environmental analysis }\end{array}$ & Denmark & Primary & $n=394$ \\
\hline $\begin{array}{l}\text { SQW Consulting } \\
\text { (2007) }\end{array}$ & Report & $\begin{array}{l}\text { Cycling: economic \& public } \\
\text { policy benefits }\end{array}$ & UK & Review & \\
\hline Su et al. (2010) & Refereed journal & $\begin{array}{l}\text { Promoting cycling via a route } \\
\text { planning tool }\end{array}$ & Canada & Primary & \\
\hline Sustrans (1999) & Information pack & Cycle tourism briefing & UK & Primary & \\
\hline Sustrans (2007) & Report & $\begin{array}{l}\text { Cycle Tourism: economic impact } \\
\text { study }\end{array}$ & UK & Primary & \\
\hline Sustrans (2008) & Report & $\begin{array}{l}\text { National Cycle Route user } \\
\text { analysis }\end{array}$ & UK & Primary & \\
\hline Tin Tin et al. (2010) & Refereed journal & $\begin{array}{l}\text { Attitudes towards policies } \\
\text { encouraging cycling }\end{array}$ & New Zealand & Secondary & $n=2,469$ \\
\hline Xing et al. (2010) & Refereed journal & $\begin{array}{l}\text { Factors affecting cycling for } \\
\text { different purposes }\end{array}$ & US & Primary & $n=581$ \\
\hline $\begin{array}{l}\text { Zlot and Schmid } \\
\text { (2005) }\end{array}$ & Refereed journal & $\begin{array}{l}\text { Relationship between physical } \\
\text { environmental factors and } \\
\text { physical activity levels }\end{array}$ & US & Secondary & $n=409,025$ \\
\hline
\end{tabular}

Although Table 3 contains economic impact figures standardized at 2010 UK prices, the studies listed are not directly comparable as they differ considerably in scale, scope, and composition. For example, Faulks et al.'s (2007) annual estimate of $£ 94.8$ million is for cycle tourism across Australia, whereas Cope, Doxford, and Hill's (1998) figures of $£ 1.7$ million and $£ 2$ million for 1997 and 1996, respectively, are for cycle tourism on a single trail in the North East of England. In terms of the scope of the studies, while Faulks et al. (2007) and Cope et al. (1998) assess only the activity of tourists, the Institute of Transport and Tourism (2008) and Picton and Bull (2003) also include local residents to derive their economic activity figures of $£ 10$ million (Taff Trail)/£24 million (Celtic Trail) and
$£ 350,000$, respectively. Finally, in those studies where both day-trippers and overnight stayers are included, the composition of the cycling population varies from $2 \%$ overnight stayers in the Celtic Trail study (Institute of Transport and Tourism, 2008) to $5 \%$ overnight stayers in the Viking Trail study (Picton \& Bull, 2003). However, other studies (e.g., Lumsdon et al.'s 2004 study of the North Sea Cycle Route) show that overnight use can be as high as $30 \%$ on some routes.

Given the incomparability of the figures in Table 3 , three meta-analyses of economic impact have been conducted to provide more powerful standardized figures for economic impact per cyclist per day at 2010 UK prices that are comparable across contexts. Unlike some of the global figures for economic 
Table 3

Economic Impact Studies Inflated and Converted to UK 2010 Prices

\begin{tabular}{|c|c|c|c|c|}
\hline Study & Cycling Provision Measured & $\begin{array}{l}\text { Year Data } \\
\text { Collected }\end{array}$ & Economic Impact & $\begin{array}{l}\text { Economic Impact } \\
\text { at } 2010 \text { UK prices }\end{array}$ \\
\hline Faulks et al. (2007) & Cycle tourists in Australia & $2004 / 5$ & Aus $\$ 213.8$ million & $£ 94,800,000$ \\
\hline Lumsdon et al. (2009) & Veloland Schweiz & 2004 & Euro 87,600,000 & $£ 68,880,000$ \\
\hline $\begin{array}{l}\text { Institute of Travel and } \\
\text { Tourism (2008) }\end{array}$ & Celtic Trail (Wales) & 2006 & $£ 21.65$ million & $£ 24,000,000$ \\
\hline Simonsen et al. (1998) & Cycle tourists in Fyn (Denmark) & 1995 & DKK79 million & $£ 12,600,000$ \\
\hline Sustrans (2007) & $\begin{array}{l}\text { North Sea Cycle Network in the } \\
\text { North East of England }\end{array}$ & 2006 & $£ 9.6$ million & $£ 10,600,000$ \\
\hline $\begin{array}{l}\text { Institute of Transport } \\
\text { and Tourism (2008) }\end{array}$ & Taff Trail (Wales) & 2006 & $£ 9.34$ million & $£ 10,000,000$ \\
\hline Simonsen et al. (1998) & $\begin{array}{l}\text { Cycle tourists in Bornholm } \\
\text { (Denmark) }\end{array}$ & 1995 & DKK45 million & $£ 7,200,000$ \\
\hline Cope et al. (1998) & $\begin{array}{l}\text { Cycle tourists on end-to-end } \\
\text { trips on the C2C Cycle Route } \\
\text { in the North of England }\end{array}$ & 1996 & $£ 1.46$ million & $£ 2,000,000$ \\
\hline Cope et al. (1998) & $\begin{array}{l}\text { Cycle tourists on end-to-end } \\
\text { trips on the C2C Cycle Route } \\
\text { in the North of England }\end{array}$ & 1997 & $£ 1.21$ million & $£ 1,700,000$ \\
\hline Bowker et al. (2007) & $\begin{array}{l}\text { Cycle tourists on the Virginia } \\
\text { Creeper Rail Trail (USA) }\end{array}$ & $2002 / 3$ & $\$ 1.2$ million & $£ 818,500$ \\
\hline Picton and Bull (2003) & Viking Trail (Kent, England) & 2003 & $£ 293,297$ & $£ 350,000$ \\
\hline
\end{tabular}

impact listed in Table 3, these normalized spend per person per day figures include the spending of those on holidays for which cycling is not the prime purpose. However, notwithstanding the standardization that the meta-analyses provide, local factors such as the strength of the local tourism economy and the quality of provision will still cause a variation from the aggregated figure in individual cases. The three meta-analyses (see Table 4) provide: a spend per person per day figure for cyclists who are not staying overnight; a spend per person per day figure for those whose trip includes an overnight stay; and an overall average figure for all cyclists (regardless of whether an overnight stay is included). The figures in Table 4 are based on a number of assumptions. Firstly, because the aim was to generate spending

Table 4

Meta-analyzed Spend per Day Inflated and Converted to UK 2010 Prices

\begin{tabular}{lll}
\hline $\begin{array}{l}\text { Cyclists Not } \\
\text { Staying Overnight }\end{array}$ & $\begin{array}{c}\text { Cyclists Staying } \\
\text { Overnight }\end{array}$ & All Cyclists \\
\hline 9 datasets & 7 datasets & 12 datasets \\
2,381 cyclists & 2,490 cyclists & 7,112 cyclists \\
$£ 7.95$ per & $£ 43.33$ per & $£ 13.38$ per \\
person per day & person per day & person per day \\
\hline
\end{tabular}

statistics that would be relevant in the UK, studies containing UK data have been weighted four times higher in the analysis than overseas studies. Secondly, in generating the spend per person per day for all cyclists, it has been assumed that there will be 10 non-overnight stayers for every cyclist staying overnight (this approximate assumption is based on the studies returned that include a ratio of nonovernight to overnight stayers).

For those cyclists not staying overnight, the meta-analysis suggests a spend per person of $£ 7.95$, which includes the spending of local residents. Local resident spend has been included because the geographical scale of what is considered to be the local economy may vary across locations, and therefore the proportion of spending to be removed will vary. However, the market segmentation metaanalysis presented in the next section can be used to identify the approximate ratio of local resident to cycling tourist spending for different geographic scales of local economy. The variation in this normalized figure across the nine datasets is from a low of $£ 4.30$ per cyclist per day on the local cyclistdominated Taff Trail in Wales, to a high of $£ 11.70$ per cyclist per day on the Virginia Creeper Trail in the US, which is a major tourist attraction in its own right (Bowker, Bergstrom, \& Gill, 2007). 
Cyclists staying overnight are estimated to spend $£ 43.33$ per person per day. Obviously, this figure is higher than the non-overnight stayers because it includes accommodation. This shows that the value per day of cyclists staying overnight is over five times that of a non-overnight stayer. Although this might be compared with the assumed volume measure of there being 10 non-overnight stayers for every cyclist staying overnight on any one day, this does not provide the full picture in terms of local economic impact, as overnight stayers are likely to use the cycling provision on multiple days during their stay (this is discussed in more detail in the market segmentation meta-analysis).

The spending figure for all cyclists of $£ 13.38$ per cyclist per day has been calculated because the economic impact of cycling provision is often derived from automatic cycling counters on trails that do not differentiate between non-overnight stayers and cyclists staying overnight. As such, it provides a useful spend per cyclist figure for generating overall spending estimates. Furthermore, this figure is derived from a very large sample of over 7,000 cyclists so, local qualitative variations in provision notwithstanding, it represents a robust estimate for UK cycling provision subject to the assumption of a ratio of 10 non-overnight stayers to 1 cyclist staying overnight. However, inevitably local economic conditions do vary, and for this reason the market segmentation meta-analysis in the next section has been conducted, which provides a more sophisticated disaggregated picture of spend per person pay day levels, but which, as noted in the conclusion to the article, also allows more bespoke local estimates to be calculated according to local data and conditions.

\section{Market Segmentation Meta-Analysis}

The previous section presented data on the local economic impact of tourism and leisure cycling (comprising the spending of both local residents and cycling tourists), with a meta-analysis calculating standardized spend per person per day figures for non-overnight, overnight, and all cyclists. While, as might be expected, these figures show a considerable difference in spend between non-overnight and overnight cyclists, there is still considerable variation within these groups. As such, this section explores how the tourism and leisure cycling market can be segmented by user group, and how cycling tourists might be differentiated from local residents. Many of the 50 included studies provide some comment on market segmentation, and these studies are used in this section to guide an exploration of the only four full datasets that could be retrieved from the search. These datasets are from the Viking Trail study (Picton \& Bull, 2003), from the Forestry Commission surveys on forest use in Scotland and Wales (covering 2004-2007), from the English Leisure Visits Survey (2005), and from Natural England's Monitor of Engagement with the Natural Environment (covering 2009/10). In total, these datasets include 1,340 detailed responses on tourism and leisure cycling behaviors and spending, which covers the activities of almost 3,500 cyclists. As elsewhere in this article, all spending figures have been inflated to 2010 UK prices.

The two obvious divisions for local economic impact purposes are between those who stay overnight and those who do not, and between residents and tourists. However, evidence suggests that further divisions are also useful. Firstly, for those staying away from home overnight, Downward, Lumsdon, and Weston (2009) note that there are two distinct groups: those that are staying in holiday accommodation in the local area that make use of cycling routes (Holidayers), and those that are on what might be seen as a traditional cycling holiday, traveling to a different destination by cycle each day (Cycle Tourers). Secondly, Downward and Lumsdon (2001) suggest that there is a significant proportion of cyclists who wish to access cycle routes by cycle (as opposed to arriving, for example, by car), and that this demand exists among both residents living near the routes and holidayers staying in nearby accommodation. This suggests that it would be useful to split residents into those living within circa 5 miles of the cycle route (Near Residents) and those living more than 5 miles away, but still within 25 miles (Far Residents), with a similar division of Near Holidayers and Far Holidayers among those staying in accommodation in the area. Finally, Downward et al. (2009) suggest that there is a relationship between the time "invested" in cycling as a tourism and leisure activity and spending. Consequently, it would appear useful to split those who are neither residents, holidayers, nor 
Table 5

Basic Characteristics of Tourism and Leisure Cycling Market Segments

\begin{tabular}{|c|c|c|c|c|c|c|}
\hline Near Residents & Far Residents & Near Day Trippers & Far Day Trippers & Near Holidayers & Far Holidayers & Cycle Tourers \\
\hline $\begin{array}{l}\text { Live within } \\
5 \text { miles }\end{array}$ & $\begin{array}{l}\text { Live between } \\
5 \text { and } 25 \text { miles }\end{array}$ & $\begin{array}{l}\text { Travel between } \\
25 \text { and } 50 \text { miles }\end{array}$ & $\begin{array}{l}\text { Travel more than } \\
50 \text { miles }\end{array}$ & $\begin{array}{l}\text { Staying within } \\
5 \text { miles }\end{array}$ & $\begin{array}{l}\text { Staying farther } \\
\text { than } 5 \text { miles }\end{array}$ & $\begin{array}{l}\text { Traveling through } \\
\text { by cycle }\end{array}$ \\
\hline \multicolumn{7}{|c|}{ At least one overnight stay } \\
\hline \multicolumn{3}{|c|}{$\begin{array}{l}\text { Economic activity not } \\
\text { additional to area }\end{array}$} & \multicolumn{4}{|c|}{ Economic activity is additional economic impact for area } \\
\hline
\end{tabular}

cycle tourers into those who have traveled a relatively short distance for the day (between 25 and 50 miles) to use the cycling route, and those who have traveled farther (more than 50 miles), using the labels Near Day Trippers and Far Day Trippers, respectively. The evidence returned therefore suggests seven segments, the basic characteristics of which are summarized in Table 5.

However, a further analysis of the evidence across the 50 sources included in the review suggests that there are other behavioral distinctions between these segments beyond how close they are staying to the cycle route, or how far they have traveled for the day. This analysis of the wider evidence returned relating to the potential different characteristics, behaviors, and spending patterns of the segments has guided the meta-analysis of the four full datasets. Table 6 provides a detailed breakdown of the characteristics, behaviors, and spending patterns derived from this meta-analysis.

The discussions above have already noted that Downward and Lumsdon (2001) suggest that a key differentiation between segments is likely to be the extent to which each segment accesses the cycle route by cycle rather than arriving by another form of transport, most often a car. While this information is not available for the Viking Trail, it does feature in the other three datasets, and the meta-analysis shows that a far greater proportion of Near and Far Residents and, to a lesser extent, of Near and Far Holidayers access the routes by bicycle than the other segments. To a certain extent, it might have been expected that a similar proportion of Near Holidayers as Near Residents would access the route by cycle, as they are each within the same distance of the route. However, Bauman et al. (2008) show that both those who are not familiar with local infrastructure and those who are less experienced cyclists will overestimate both distance and travel time by cycle. Later discussions suggest that there is a greater proportion of less experienced cyclists in the Near Holidayers segment than among Near Residents, and also a greater proportion of families. Collectively, these factors might explain the lower proportion of cyclists in the Near Holidayers segment accessing routes by cycle.

Each of the four datasets contains information on spending patterns, and so it has been possible

Table 6

Characteristics, Behaviors, and Spending Patterns of Tourism and Leisure Cycling Market Segments

\begin{tabular}{|c|c|c|c|c|c|c|c|}
\hline & $\begin{array}{l}\text { Near } \\
\text { Residents }\end{array}$ & $\begin{array}{c}\text { Far } \\
\text { Residents }\end{array}$ & $\begin{array}{l}\text { Near Day } \\
\text { Trippers }\end{array}$ & $\begin{array}{l}\text { Far Day } \\
\text { Trippers }\end{array}$ & $\begin{array}{l}\text { Near } \\
\text { Holidayers }\end{array}$ & $\begin{array}{c}\text { Far } \\
\text { Holidayers }\end{array}$ & $\begin{array}{l}\text { Cycle } \\
\text { Tourers }\end{array}$ \\
\hline Volume (\% of market) & $13 \%$ & $41 \%$ & $19 \%$ & $10 \%$ & $9 \%$ & $7 \%$ & $0.9 \%$ \\
\hline Spend per cyclist per day (2010 prices) & $£ 4.55$ & $£ 6.54$ & $£ 9.71$ & $£ 15.48$ & $£ 36.62$ & $£ 48.97$ & $£ 29.77$ \\
\hline $\begin{array}{l}\text { Spend attributable to cycling provision } \\
\text { per cyclist per stay (2010 prices) }\end{array}$ & $£ 4.55$ & $£ 6.54$ & $£ 9.71$ & $£ 15.48$ & $£ 130.33$ & $£ 148.36$ & $£ 29.77$ \\
\hline Value (\% of economic activity) & $4 \%$ & $19 \%$ & $14 \%$ & $11 \%$ & $24 \%$ & $25 \%$ & $2.0 \%$ \\
\hline Average group size & 2.09 & 2.53 & 2.72 & 3.12 & 3.04 & 2.85 & 2.12 \\
\hline Percentage accessing route by cycle & $69 \%$ & $48 \%$ & $20 \%$ & $6 \%$ & $33 \%$ & $30 \%$ & - \\
\hline Trip distance (miles) & 13.8 & 18.6 & 22.6 & 35.19 & 34.06 & 27.45 & - \\
\hline Duration of trip & $1 \mathrm{~h}, 32 \mathrm{~min}$ & 2 h, 5 min & 2 h, 30 min & $3 \mathrm{~h}, 55 \mathrm{~min}$ & $3 \mathrm{~h}, 47 \mathrm{~min}$ & $2 \mathrm{~h}, 53 \mathrm{~min}$ & - \\
\hline Percentage of trips longer than 3 hours & $18 \%$ & $30 \%$ & $40 \%$ & $64 \%$ & $69 \%$ & $53 \%$ & - \\
\hline
\end{tabular}


to establish robust spending estimations for each market segment. As might be expected, the spend per cyclist per day is much greater for Near and Far Holidayers and Cycle Tourers than for the other segments because spending on accommodation is included. However, the spending of residents and day trippers shows that spend per cyclist increases as distance traveled for the day to get to the cycle route increases, with Near Residents spending the least (£4.55) and Far Day Trippers spending the most (£15.48). Of those staying overnight, the daily spend of Cycle Tourers (£29.77) is the lowest, and this may be explained by findings in Ritchie (1998) and Simonsen et al. (1998) that this segment tends to utilize low-cost accommodation such as camping sites and youth hostels. There is a significant difference between the daily spend of Near Holidayers (£36.62) compared to Far Holidayers (£48.97). However, further analysis of the datasets shows that this difference is almost entirely accounted for by a higher spend on accommodation, suggesting that in the immediate area around cycle routes (particularly those in forests and other natural environments), higher quality accommodation is harder to find, and so holidayers seeking accommodation at the higher end of the market cannot stay close to cycle routes.

At this point it is useful to compare estimates that can be derived from the market segmentation analysis for non-overnight, overnight, and all cyclists shown in Table 6 with those estimated in the economic impact meta-analyses shown earlier in Table 4. As the economic impact meta-analyses are derived from three times as many studies and a more than four times greater sample size, this provides a useful verification of the extent to which the market segmentation meta-analysis is representative of the wider literature for which full datasets were not available. The estimate for non-overnight cyclists from the market segmentation meta-analysis (the average spend of Near Residents, Far Residents, Near Day Trippers, and Far Day Trippers) is $£ 8.03$, which varies by only $£ 0.08$ (1\%) from the estimate of $£ 7.95$ from the economic impact meta-analysis, while the estimate for overnight cyclists (the average spend of Near Holidayers, Far Holidayers, and Cycle Tourers) is $£ 41.37$, varying by $£ 1.96$ (4\%) from the economic impact metaanalysis estimate of $£ 43.33$. Finally, the estimate of average spend for all seven market segments in Table 6 is $£ 13.38$, which varies by $£ 0.28$ (2\%) from the estimate of $£ 13.66$ from the economic impact meta-analysis. These comparisons suggest that the market segmentation meta-analysis is highly representative of the wider evidence for the economic impact of tourism and leisure cycling.

One of the problems associated with assessing the economic impact of Near and Far Holidayers has been deciding how much of the total spend during the stay in the area should be attributed to cycling tourism. In fact, as the earlier discussion of the literature notes, some economic impact studies would exclude ALL of the spending of those Near and Far Holidayers for whom cycling is not the prime purpose of the trip. However, the four datasets included in the market segmentation meta-analysis each include information on both the length of the stay in the area and the number of times during the stay that the holidayers used the cycle routes. These data show that Near Holidayers' average stay in the area is 7.6 days, and that they tend to use the cycle route on roughly half of the days they are in the area (average 3.6 days), whereas Far Holidayers tend to stay for a shorter average time (perhaps explaining why they are prepared to spend more on accommodation) of 4.7 days, but they tend to use the cycle routes on roughly two thirds of the days they are in the area (average 3.0 days). By attributing the spending (including accommodation) on days that Near and Far Holidayers use the cycle routes to cycling tourism, a spend per cyclist per stay can be estimated, which shows that the value of Near and Far Holidayers per visit to the area is much higher than that of any other segment, including Cycle Tourers, who it is assumed will only stay in the local area for 1 night of their tour (see Fig. 1).

In fact, there may be an argument that when Near and Far Holidayers use cycle routes on more than half of the days they are in the area, ALL of their spending during their stay should be attributed to cycling tourism. This is because the use of the cycle routes on more than half of the days during their stay suggests that cycling plays such an important part in their trip that without the cycle routes these holidayers would not have visited the area at all. However, for this analysis the more conservative approach of attributing spending from the days cycled during the stay to cycling tourism has been 


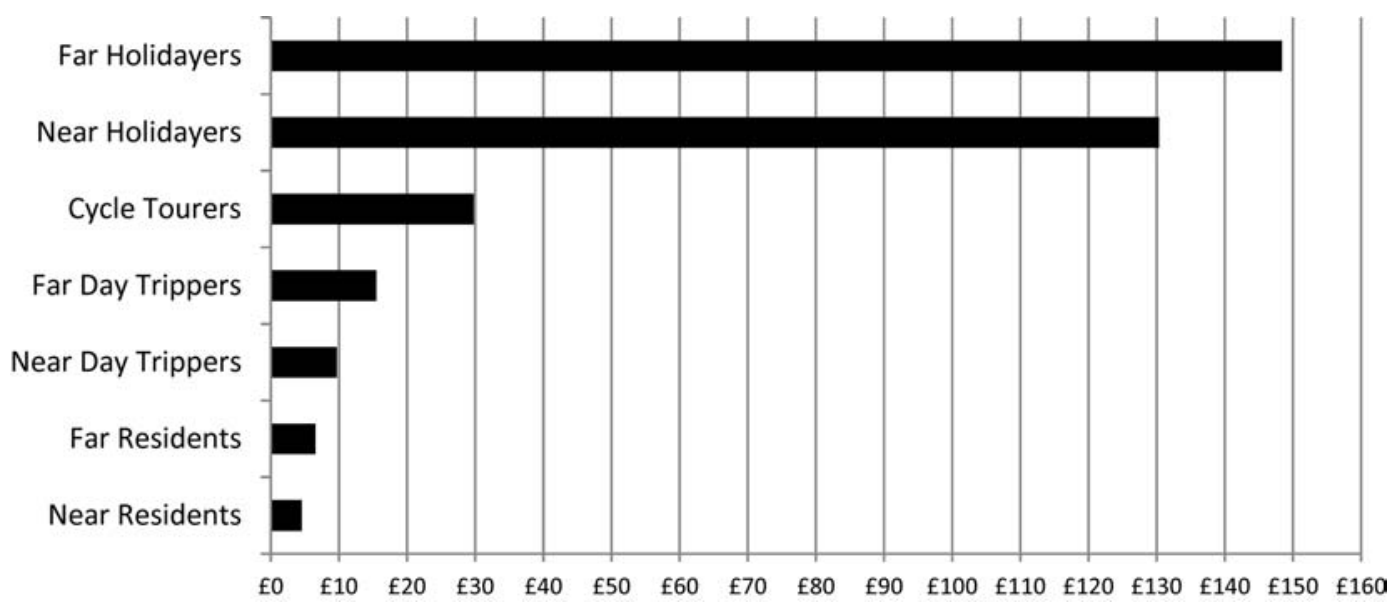

Figure 1. Spend per person per stay of tourism and leisure cycling market segments.

taken. This approach allows the inclusion of impact from tourists for whom cycling is not the prime holiday purpose (thus avoiding underestimating economic impact) without including spending from the entire trip (thus risking overestimating economic impact).

Alongside the spend per day and spend per stay figures, the datasets also allow an estimation of the volume (relative size) of each of the market segments. This shows that the greatest volume of use of cycle routes is by residents (55\%), although Far Residents (41\%) outnumber Near Residents (13\%) by around three to one. This is largely due to the greater size of the area between 5 and 25 miles away, and thus the greater size of this population. Of the other groups, the Near Day Trippers segment (19\%) is roughly twice the size of the Far Day Trippers segment (10\%), which is roughly the same size as the Near Holidayers segment (9\%), with the Far Holidayers segment (7\%) slightly smaller. Perhaps surprisingly, the size of the Cycle Tourers segment, which is probably what would most immediately come to mind for most people as the archetypal type of cycling tourism, is negligible at less than $1 \%$.

Similar percentages for those described above for volume can be calculated for value. This shows that the two residents segments account for $23 \%$ of the economic activity attributable to the cycling routes, but, of course, this activity does not represent additional economic impact for the area. Approximately a further quarter of market value is attributable to the Near Day Trippers (14\%) and Far Day Trippers (11\%) segments, with around half attributable to Near Holidayers (24\%) and Far Holidayers (25\%). As with volume, the value of the Cycle Tourers market segment is negligible at only $2 \%$. Figure 2 illustrates the volume and value of each of the market segments.

Figure 2 shows that the greatest volume is generated by Far Residents, but unfortunately the value that is associated with this does not represent an additional economic impact for the local area. The extent of the economic impact of tourism and leisure cycling to a local area (i.e., the cycling tourism element) is largely dependent on where the area concerned wishes to draw a geographical boundary between spending that is internal to the local economy and spending that represents additional economic impact. The assumption of the segmentation developed here is that money originating from outside a 25-mile boundary might reasonably represent additional impact, and if this is the case, then the analysis estimates that over three quarters of economic activity (77\%) generated by tourism and leisure cycling is attributable to cycling tourism and thus provides additional economic impact to the local area.

However, if an area wishes to regard a wider geographical boundary of 50 miles as "local," then the Near Day Trippers segment, which as Figure 2 shows is the second most significant segment in 


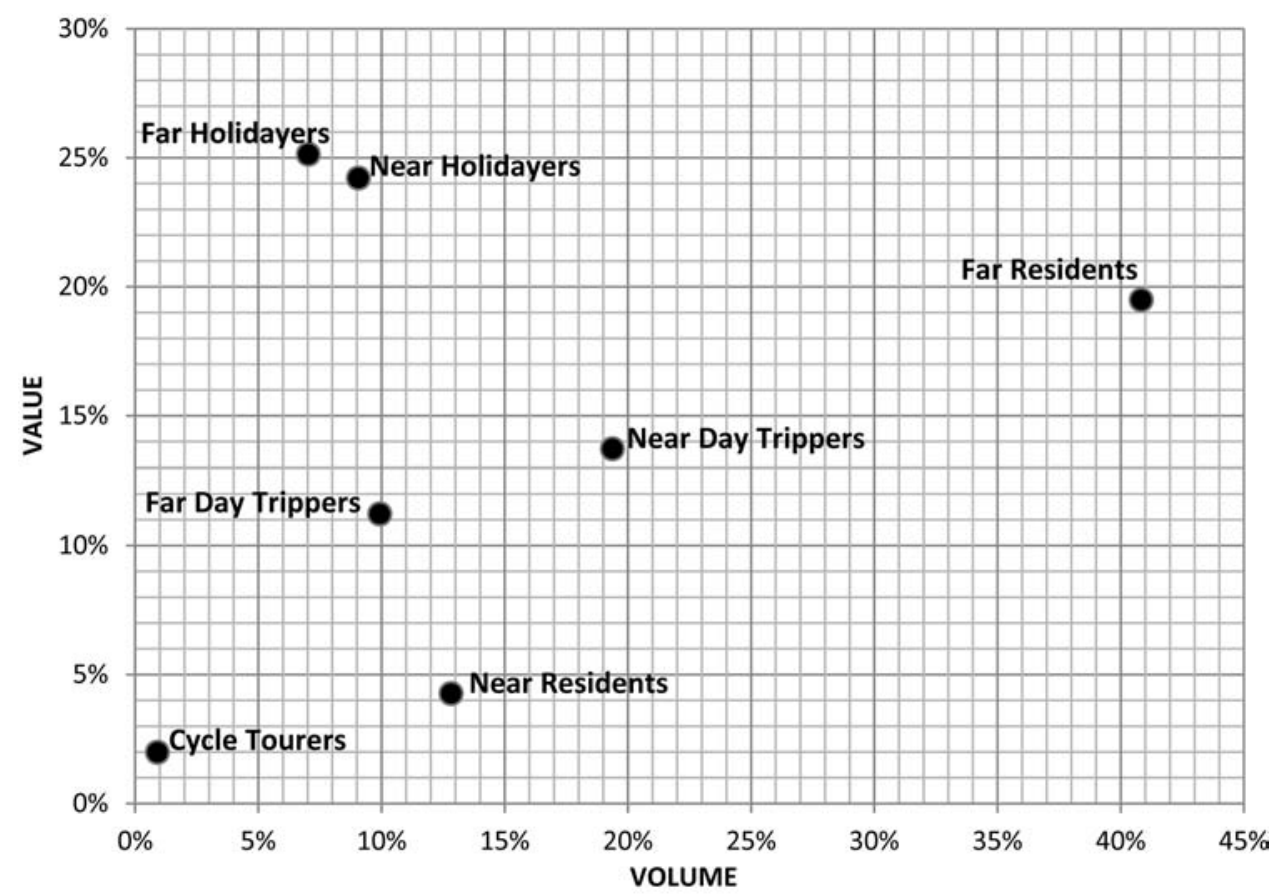

Figure 2. Volume and value of tourism and leisure market segments.

terms of volume and value, should not be counted as providing additional economic impact. With this wider definition of "local," the analysis estimates that just under two thirds of economic activity (63\%) generated by tourism and leisure cycling would be attributable to cycling tourism and thus provides additional economic impact for the local area.

Figures 1 and 2 suggest various strategies to increase the local economic impact of cycling tourism. Because the spend per stay of Near and Far Holidayers is so high (for every stay by a Far Holidayer, more than nine trips by a Far Day Tripper are required to generate the same local economic impact), an obvious strategy would be to target these market segments, although their comparatively low volume might suggest that the overall market size from which to draw might be limited. Alternatively, assuming a definition of "local" that considers Near Day Trippers (those traveling from between 25 and 50 miles away) to be cycling tourists, seeking to generate repeat visits among this group might be a fruitful approach. Similarly, seeking to increase the volume of Far Day Trippers may be another potential strategy, although given the longer distance traveled, repeat visits are likely to be less frequent than those by Near Day Trippers.

Of course, as well as strategies to increase the numbers of visitors in each of the market segments, another approach is to seek to increase the spend per person. Downward et al. (2009) suggest that the two key factors that increase spending are group size and duration of trip. The meta-analysis (Table 6) shows that the average group size for Near Residents (2.09), which also has the lowest spend per cyclist, is significantly lower than that of all the other groups. This is because many Near Residents cycle alone, and use the cycle routes for shorter journeys (average journey length is just under 14 miles). While the average group sizes for the other segments are all over 2.5 , there is a general upward trend with spend per cyclist (although there is a slight drop in group size for the segments staying overnight). In terms of trip duration, again Near Residents' trips are the shortest by some way. However, the spend per cyclist of Far Day Trippers, whose average duration of trip is almost 4 hours, is around 60\% higher than that of Near Day Trippers, and more than $130 \%$ higher than Far Residents, both of whom have an average trip 
duration of less than 3 hours. These figures reinforce Downward et al.'s (2009) analysis, which suggests that there is a significant increase in spend per person when the duration of trip is higher than 3 hours, and the meta-analysis shows that almost two thirds of Far Day Trippers (64\%) have a trip duration of over 3 hours. This makes intuitive sense, as a trip of more than 3 hours is likely to include a stop for a meal or a drink at a pub or café. Furthermore, such stops are likely to be more socially significant if the group is larger, and thus larger group sizes are likely to increase the spend per person on such stops.

The nature (or type) of cycling participation among those in each of the market segments might be considered on two dimensions: cycling experience and cycling regularity. Of course, Cycle Tourers will be almost exclusively experienced cyclists, and most will cycle regularly. There is also an implication in some of the evidence (Downward \& Lumsdon, 2001; Lumsdon et al., 2004; Picton \& Bull, 2003) that there is likely to be a greater than average proportion of regular and experienced cyclists in the Near and Far Residents segments. However, while there are likely to be many regular and experienced cyclists in the Near and Far Day Trippers and the Near and Far Holidayers market segments, there is evidence to suggest that these segments will include a greater than average proportion of what might be termed "casual recreationalist cyclists" (Downward \& Lumsdon, 2001) — cyclists who, while they may be experienced, do not necessarily cycle regularlymixed with cyclists who are both inexperienced and do not cycle regularly (Picton \& Bull, 2003), often in family groups. These groups are likely to be prone to more "touristic" behaviors (such as stopping more regularly for coffee, ice cream, and food), and thus are likely to spend more. Such groups are also likely to include more women (among whom participation in tourism and leisure cycling is much lower than men: Cope et al., 2003; Downward et al., 2009; Garrard, Crawford \& Hakman, 2006; Garrard, 2003; Garrard, Crawford \& Hakman, 2006; Sustrans, 2008), which the meta-analysis shows is associated with higher spending.

In summary, the meta-analysis of the four datasets, supported by the wider evidence base, provides robust evidence for seven tourism and leisure cycling market segments and their associated behaviors and spending patterns. The analysis shows that the market volume and value of Cycle Tourers is negligible, and that the greatest market volume comes from Near Day Trippers, with the greatest value attributable to Far Holidayers. However, the spend per stay of Near and Far Holidayers attributable to cycling tourism is around 10 times higher than that of the Near and Far Day Trippers market segments. Assuming that the local area is defined as the area within 25 miles of the cycle routes, over three quarters of economic activity attributable to tourism and leisure cycling (77\%) can be considered as being derived from cycling tourism and thus represents additional economic impact for the local area.

\section{Conclusions}

This article has, through a systematic review and meta-analyses of worldwide evidence, provided estimates for the spend per day of overnight, nonovernight, and all tourism and leisure cyclists. It has also, through a further meta-analysis, developed a market segmentation of the market for tourism and leisure cycling that can inform the provision strategies of local policy makers, planners. and providers for recreational cycling to maximize local economic impact.

While the market segmentation meta-analysis provides estimates for the volume and value of each market segment, it also allows these estimates to be refined according to local knowledge or conditions. For example, the meta-analysis shows that the ratio of residents to tourists is $54: 46$, and that cycling tourists represent $77 \%$ of the value attributable to local cycling provision. However, if local surveys of a particular route showed that the proportion of local residents was lower, then the data presented in this article could be used to adjust market value estimates accordingly, and if annual usage figures were available (from, for example, automatic cycling counters), then such adjusted market value estimates could be used to calculate bespoke economic impact estimates for particular local areas.

Similarly, the data presented in the market segmentation meta-analysis could be used to inform local planning, policy, and provision according to local conditions. For example, if cycle path provision is extensive and varied, and there is a good stock of high-quality accommodation, then promoting 
such cycling provision as part of general advertising for short breaks to the high-value Far Holidayers market segment could be a fruitful strategy. Alternatively, if large urban areas exist in relatively close proximity (between 25 and 50 miles) to local cycling provision, then seeking to generate regular repeat visits among urban dwelling Near Day Trippers may be a productive approach. Product development might also be informed by the market segmentation data. For example, if regular repeat visits by Near Day Trippers are to be targeted, then clearly signed routes of between 15 and 25 miles should be developed, alongside clear advice about how to access the route by cycle (or by a combination of cycle and public transport, including the development of cycling-friendly local public transport system) for the $40 \%$ of Near Day Trippers who do not wish to access routes by car.

The market segmentation meta-analysis supports Weed and Bull's (2009) contention that sports tourism should not be analyzed at the trip level, but according to the extent to which sports tourism activities affect trip decisions. Table 6 and Figure 2 show that holidayers for whom cycling is likely to be a key part of trip decisions, but not the primary purpose of the trip (i.e., Near and Far Holidayers), comprise $16 \%$ of the volume and $49 \%$ of the value of tourism and leisure cycling, and if local residents are excluded, 35\% of the volume and $64 \%$ of the value of cycling tourism. As such, if only trips where cycling tourism is considered to be the prime trip purpose are included in assessments of economic impact, then it is likely that the value of cycling tourism to local economies would be considerably underestimated, perhaps by up to half. Consequently, a full and robust assessment of the impact of sports tourism requires not that sports tourism trips are considered, but that the role of sports tourism activities in trip decisions is examined.

The data in Table 6 and Figure 2 also show, perhaps surprisingly, that the volume and value of cyclists who travel from place to place, staying in a different place each night (Cycling Tourers), are virtually negligible at less than $1 \%$ and $2 \%$ of the tourism and leisure cycling market, respectively. This suggests that future research on cycling tourism should focus not on such dedicated Cycle Tourers that many would perhaps consider to be the archetypal cycling tourists, but on less dedicated but far more prevalent "casual recreationalist cyclists” (Downward \& Lumsdon, 2001), who are interested in shorter trips, with more stops for refreshments and socializing, and who often travel in family groups.

\section{Notes}

${ }^{1}$ We are defining the tourism and leisure cycling market broadly to involve recreational participation in all forms of cycling (e.g., road cycling, trail cycling, off road cycling), but excluding participation and spectating at competitive cycling events.

${ }^{2}$ It is acknowledged that there may be further local economic impacts from health cost savings attributable to the use of local cycling provision by local residents, and that there is likely to be an economic value attributable to any environmental costs and benefits. However, these impacts are not considered in this article, which focuses solely the direct impact of spending, and on identifying the proportion of spending that is additional to the local economy. The article also does not consider the potential multiplier effect of direct spending attributable to tourists. This is because the size and extent of such multipliers varies considerably according to the very different structures of local economies and thus cannot be accounted for within a metaanalysis that seeks to provide generalizable spending estimates. Consequently, an analysis of multiplier effects is most appropriately added at a local level according to local economic conditions.

\section{Acknowledgment}

This study was funded by Kent County Council Economic Development Unit.

\section{References}

Bauman, A., Rissel, C., Garrard, J., Ker, I., Speidel, R., \& Fishman, E., (2008). Cycling: Getting Australia moving: Barriers, facilitators \& interventions to get more Australians physically active through cycling. Melbourne: Cycling Promotion Fund.

Berrigan, D., Troiano, R., McNeel, T., DiSogra, C., \& BallardBarbash, R. (2006). Active transportation increases adherence to activity recommendations. American Journal of Preventative Medicine, 31(3), 210-216.

Bhat, C., \& Lockwood, A. (2004). On distinguishing between physically active and physically passive episodes and between travel and activity episodes: An analysis of weekend recreational participation in the San Francisco Bay Area. Transportation Research Part A: Policy \& Practice, 38(8), 573-592.

Bowker, J. M., Bergstrom, J. C., \& Gill, J. (2007). Estimating the economic value and impacts of recreational trails: 
A case study of the Virginia Creeper Rail Trail. Tourism Economics, 13(2), 241-260.

Bowles, H., Rissel, C., \& Bauman, A. (2006). Mass community cycling events: Who participates and is their behavior influenced by participation? International Journal of Behavioral Nutrition and Physical Activity, 3(39). Retrieved from http://link.springer.com/article/ 10.1186\%2F1479-5868-3-39

Breakell, B. (2006). Activity tourism-Developing cycle tourism in the North York Moors and coast. Countryside Recreation, 14(2), 14-16.

Brown, T., O’Conner, P., \& Barkatasas, A. (2009). Instrumentation and motivations for organised cycling: The development of the Cyclist Motivation Instrument (CMI). Journal of Sports Science and Medicine, 8, 211-218.

Bull, C. (2006). Racing cyclists as sports tourists: The experiences and behaviors of a case study group of cyclists in East Kent, England. Journal of Sport \& Tourism, 11(3/4), 259-274.

Bull, C., \& Lovell, J. (2007). The Impact of hosting major sporting events on local residents: An analysis of the views and perceptions of Canterbury Residents in relation to the Tour de France 2007. Journal of Sport \& Tourism, 12(3/4), 229-248.

Card, D., Kluve, J., \& Weber, A. (2010). Active labour market policy evaluations: A meta-analysis. The Economic Journal, 120(548), 452-477.

Cavill, N., \& Davis, A. (2007). Cycling and health-What's the evidence? London: Cycling England.

Chatzisarantis, N. L. D., Hagger, M. S., Biddle, S. J. H., Smith, B., \& Wang, J. C. K. (2003). A meta-analysis of perceived locus of causality in exercise, sport, and physical education contexts. Journal of Sport \& Exercise Psychology, 25, 284-306.

Chiu, L., \& Kriwoken, L. (2003). Managing recreational mountain biking in Wellington Park, Tasmania, Australia. Annals of Leisure Research, 6(4), 339-361.

Cope, A., Cairns, S., Fox, K., Lawlor, A., Lockie, M., Lumsdon, L., Riddoch, C., \& Rosen, P. (2003). The UK National Cycle Network: An assessment of the benefits of a sustainable transport infrastructure. World Transport Policy \& Practice, 9(1), 6-17.

Cope, A., Doxford, D., \& Hill, A. (1998). Monitoring tourism on the UK's first long-distance cycle route. Journal of Sustainable Tourism, 6(3), 210-223.

Coren, E., \& Fisher, M. (2006). The conduct of systematic research reviews for SCIE knowledge reviews. London: Social Care Institute for Excellence.

Crouch, D. (1995). A meta-analysis of tourism demand. Annals of Tourism Research, 22(1), 103-118.

de Geus, B., de Bourdeaudhuij, I., Jannes, C., \& Meeusen, R. (2008). Psychosocial and environmental factors associated with cycling for transport among a working population. Health Education Research, 23(4), 697-708.

Desbordes, M. (2007). A review of the economic impact studies done on the Tour de France: Methodological aspects and first results. International Journal of Sport Management and Marketing, 2(5/6), 526-540.
Dill, J. (2009). Bicycling for transportation and health: The role of infrastructure. Journal of Public Health Policy, 30, S95-S110.

Downward, P., \& Lumsdon. L. (2001). The development of recreational cycle routes: An evaluation of user needs. Managing Leisure, 6, 50-60.

Downward, P., Lumsdon, L., \& Weston. R. (2009). Visitor expenditure: The case of cycle recreation and tourism. Journal of Sport \& Tourism, 14(1), 25-42.

EcoGIS. (2002). Submission on cycle tourism to the tourism strategy group. Paper prepared by EcoGIS on behalf of the Cycling Promotion Fund of Australia and Bicycle Federation of Australia.

Faulks, P., Ritchie, B., \& Dodd, J. (2008). Bicycle tourism as an opportunity for re-creation and restoration? Investigating the motivations of bike ride participants. Paper presented at the New Zealand Tourism and Hospitality Research Conference, Hanmer Springs, New Zealand.

Faulks, P., Ritchie, B., \& Fluker, M. (2007). Cycle tourism in Australia: An investigation into its size and scope. Gold Coast: Sustainable Tourism Cooperative Research Centre.

Forward, S. (1999). Behavioural factors affecting the intention to cycle. In Proceedings of Velo-City, the 11th International Bicycle Planning Conference (pp. 608-626), Graz, Austria, April 13-16.

Fraietta, J. (2004). Cycle tourism research summary. Paper prepared for Alberta Economic Development, Alberta, Canada.

Gammon, S., \& Robinson, T. (2003). Sport and tourism: A conceptual framework. Journal of Sport Tourism, 8(1), 21-16.

Garrard, J. (2003). Healthy revolutions: Promoting cycling for women. Health Promotion Journal of Australia, 14, 213-215.

Garrard, J., Crawford, S., \& Hakman, N. (2006). Revolutions for women: Increasing women's participation in cycling for recreation and transport. Australia: School of Health and Social Development, Deakin University.

Gatersleben, B., \& Haddad, H. (2010). Who is the typical bicyclist? Transportation Research: Part F, 13(1), $41-48$.

Gibson, H., \& Yiannakis, A. (2002). Tourist roles: Needs and the lifecourse. Annals of Tourism Research, 29(2), 358-383.

Green, B. C., \& Jones, I. (2005). Serious leisure, social identity and sport tourism. Sport in Society, 8(2), 164-181.

Greenwood, C., \& Yeoman, I. (2006). Forecast for cycle tourism in Scotland to 2015. Retrieved from http://www. visitscotland.org/pdf/cycling 2006 to 2015.pdf

Greig, R. (2005). Cycling promotion in Western Australia. Bicycling Federation of Australia: Planning for Health Communities Conference, Brisbane, Australia, October.

Hudson, I. (2001). The use and misuse of economic impact analysis: The case of professional sports. Journal of Sport \& Social Issues, 25(1), 20-39.

Hunter, J., \& Schmidt, F. (1990). Methods of meta-analysis: Correcting error and bias in research findings. Newbury Park, CA: Sage. 
Institute of Transport and Tourism. (2008). The economic impact of cycling and walking in the Celtic and Taff Trails. Lancashire, UK: Author.

Kahlmeier, S., Racioppi, F., Cavill, N., Rutter, H., \& Oja, P. (2010). "Health in all policies" in practice: Guidance and tools to quantifying the health effects of cycling and walking. Journal of Physical Activity \& Health, 7(Suppl. 1), S120-S125.

Kamphuis, C., Giskes, K., Kavanagh, A., Thornton, L., Thomas, L., van Lenthe, F., Mackenback, J., \& Turrell, G. (2008). Area variation in recreational cycling in Melbourne: A compositional or contextual effect? Journal of Epidemiology \& Community Health, 62(10), 890-898.

Lamont, M. (2010). Cycle tourism in Australia: Exploring the whole tourism system. Saabrücken: Lambert Academic Publishing.

Lawlor, D., Ness, A., Cope, A., Davis, A., Insall, P., \& Riddoch, C. (2003). The challenges of evaluating environmental interventions to increase population levels of physical activity: The case of the UK National Cycle Network. Journal of Epidemiology and Community Health, 57(2), 96-101.

Lim, C. (1999). A meta-analytic review of international tourism demand. Journal of Travel Research, 37(3), 273-284.

Lumsdon, L. (1996). Cycle tourism in Britain. Insights, D27-D32.

Lumsdon, L. (2000). Transport and tourism-A model for sustainable development? Journal of Sustainable Development, 8(5), 361-377.

Lumsdon, L. (1999). Long distance cycle routes: Evaluating the tourism potential. In Proceedings of In Velo-City, the 11th International Bicycle Planning Conference (pp. 234-238), Graz, Austria, April 13-16.

Lumsdon, L., Downward, P., \& Cope, A. (2004). Monitoring of cycle tourism on long distance trails: The North Sea Cycle Route. Journal of Transport Geography, 12(11), 13-22.

Lumsdon, L., Weston, R., McGrath, P., Davies, N., Peeters, P., Eijgelaar, E., \& Piket, P. (2009). The European cycle route network, Eurovelo. Brussels: European Parliament.

Maine Department of Transportation. (2001). Bicycle tourism in Maine: Economic impacts and marketing recommendations. Maine: Author.

Manfredo, M., Driver, B., \& Tarrant, M. (1996). Measuring leisure motivation: A meta-analysis of the recreation experience preference scales. Journal of Leisure Research, 28(3), 188-213.

Mann, C., \& Absher., J. (2008). Recreation conflict potential and management implications in the northern/central Black Forest Nature Park. Journal of Environmental Planning \& Management, 51(3), 363-380.

Mason, P., \& Leberman, S. (2000). Local planning for recreation and tourism: A case study of mountain biking from New Zealand's Manawatu Region. Journal of Sustainable Tourism, 8(2), 97-115.

Mintel. (2007). Leisure intelligence: Cycling holidays. London: Author.
Mintel. (2009). Cycling holidays UK. London: Author.

Moore, C., Cope, A., \& Bulmer, A. (2006). The role of trafficfree routes in encouraging cycling among excluded groups. World Transport Policy and Practice, 12(2), 21-35.

Natural England. (2006). England leisure visits: Report of the 2005 survey. London: Author.

Papon, F. (1999). A threefold classification of French cyclists: A slight lessening of the down market image of the bicycle. In Proceedings of In Velo-City, the 11th International Bicycle Planning Conference (pp. 486489), Graz, Austria, April 13-16.

Picton, K., \& Bull, C. (2003). The economic impact of cycling on the Viking Trail in Kent. Report to Kent Highways from Canterbury Christ Church University.

Pucher, J., Buehler, R., Bassett, D., \& Dannenberg, A. (2010). Walking and cycling to health: A comparative analysis of city, state, and international data. American Journal of Public Health, 100(10), 1986-1992.

Pucher, J., Garrard, J., \& Greaves, S. (2011). Cycling down under: A comparative analysis of cycling trends and policies in Sydney and Melbourne. Journal of Transport Geography, 19, 332-345.

Quinn, M., \& Chernoff, G. (2010). Mountain biking: A review of the ecological effects: A literature review for Parks Canada-National Office (Visitor Experience Branch). Calgary: Miistakis Institute.

Regeneris Consulting. (2005). Economic and social benefits of countryside access routes in the North East. Report for the Countryside Agency, Cheltenham.

Rissel, C., Merom, D., Bauman, A., Garrad, J., Ming Wen, L., \& New, C. (2010). Current cycling, bicycle path use, and willingness to cycle more-Findings from a community survey of cycling in southwest Sydney, Australia. Journal of Physical Activity \& Health, 7(2), 267-272.

Ritchie, B. (1998). Bicycle tourism in the South Island of New Zealand: Planning and management issues. Tourism Management, 19(6), 567-582.

Ritchie, B., Tkaczynski, A., \& Faulks, P. (2010). Understanding the motivation and travel behavior of cycle tourists using involvement profiles. Journal of Travel \& Tourism Marketing, 27(4), 409-425.

Robinson, T., \& Gammon, S. (2004). A question of primary and secondary motives: Revisiting and applying the sport tourism framework. Journal of Sport Tourism, 9(3), 221-233.

Simonsen, P., \& Jorgenson, B. (1996). Cycling tourism: Environmental and economical sustainability? (Unpublished report). Bornholm, Denmark: Research Centre of Bornholm.

Simonsen, P. S., Jorgensen, B., \& Robbins, D. (1998). Cycling tourism: An economic and environmental sustainable form of tourism? Bornholm: Unit of Tourism Research, Research Centre of Bornholm.

Sofield, T. (2003). Sports tourism: From binary division to quadripartite construct. Journal of Sport Tourism, 8(3), 144-165.

South Australia Tourism Commission. (2002). Fast facts: Cycling tourism fact sheet. Adelaide: Author. 
South Australia Tourism Commission. (2005). Cycle tourism strategy 2005-2009. Adelaide: Author.

SQW Consulting. (2007). Valuing the benefits of cycling (a report to Cycling England). London: Author.

Standeven, J., \& De Knop, P. (1999). Sport tourism. Champaign, IL: Human Kinetics.

Su, J., Winters, M., Nunes, M., \& Brauer, M. (2010). Designing a route planner to facilitate and promote cycling in Metro Vancouver, Canada. Transportation Research Part A: Policy \& Practice 44(7), 495-505.

Sustrans (1999). Cycle tourism information pack TT21. Bristol: Author.

Sustrans. (2007). The economic impact of cycle tourism in North East England: Executive summary. Bristol: Author.

Sustrans. (2008). The national cycle network: Route user monitoring report-to end 2008. Bristol: Author.

Tin Tin, S., Woodward, A., Thornley, S., Langley, J., Rodgers, A., \& Ameratunga, S. (2010). Cyclists' attitudes toward policies encouraging bicycle travel: Findings from the Taupo bicycle study in New Zealand. Health Promotion International, 25(1), 54-62.

Tranfield, D., Denyer, D., \& Smart, P. (2003). Towards a methodology for developing evidence-informed management knowledge by means of systematic review. British Journal of Management, 14(3), 207-222.
Wagner, D. M. (2002). Comparing European cities tourism guest surveys: An intelligent meta-analytical approach. In K. W. Wober (Ed.), City Tourism 2002: Proceedings of European Cities Tourism's International Conference in Vienna. Vienna, Austria: Springer-Verlag.

Weed, M. (2006). Undiscovered public knowledge: The potential of research synthesis approaches in tourism research. Current Issues in Tourism, 9(3), 256-268.

Weed, M., \& Bull, C. (2009). Sports tourism: Participants, policy and providers (2nd ed.). Oxford: Elsevier.

Wales Tourist Board. (2002). Moving up a gear: A cycle tourism strategy for Wales. Cardiff: Author.

Wolf, F. M. (1986). Meta-analysis: Quantitative methods for research synthesis. London: Sage.

Wood, P. (2000). Meta-analysis. In G. M. Breakwell, S. Hammond, \& C. Fife-Schaw (Eds.), Research methods in psychology (2nd ed.). London: Sage.

Xing, Y., Handy, S., \& Mokhtarian, P. (2010). Factors associated with proportions and miles of bicycling for transportation and recreation in six small US cities. Transportation Research: Part D, 15(2), 73-81.

Zlot, A., \& Schmid, T. (2005). Relationships among community characteristics and walking and bicycling for transportation or recreation. American Journal of Health Promotion, 19(4), 314-317. 